\title{
Research on Routing Optimization of Regional Logistics Based on Gravity Model: A Case of Blue and Yellow Zones*
}

\author{
Haiqing Hu, Yang Li \\ Shandong Yingcai University, Jinan, China. \\ Email: huhqkelly@163.com, cnjnly@163.com \\ Received November $4^{\text {th }}, 2013$; revised November $20^{\text {th }}$, 2013; accepted December $5^{\text {th }}, 2013$ \\ Copyright (c) 2013 Haiqing Hu, Yang Li. This is an open access article distributed under the Creative Commons Attribution License, \\ which permits unrestricted use, distribution, and reproduction in any medium, provided the original work is properly cited.
}

\begin{abstract}
The structure is the basic attribute of everything. The structure of logistics network is composed of logistics nodes and logistics routes, however the logistics cost mainly happens on the function the logistics route undertakes. So logistics routing optimization is the key to reduce logistics cost. As logistics is the hygiene factor of regional economic development, this article studied on logistics routing optimization by applying the demand of the regional economic development as a starting point, using the spatial interaction theory, building a method of the regional logistics link optimization based on the gravity model, and taking blue and yellow zones as the background to illustrate the rationality and feasibility of this method.
\end{abstract}

Keywords: Gravity Model; Routing Optimization; Blue and Yellow Economic Zones; Logistics Network

\section{Introduction}

Logistics is the hygiene factor of social and economic development, so the regional logistics must meet the demand of the regional economic development. As a basic economic activity, logistics is also one of industries constituting the regional economy. Seen in this light, the logistics of the regional economic development is not only a hygiene factor, but also an incentive factor of the regional economic development. So first of all, logistics should be set as the security condition of the regional economic development and secondly it can be an industry as a key support in the area with logistics advantages.

Structure is the basic attribute of everything. According to the system science, it is relatively stable contact way of the inherent manifestations of organizational procedures and temporal relationship between the various elements within the system. Logistics network structure is the basic problem of the logistics network. It is composed of logistics nodes and logistics routes. Logistics nodes assume the function of logistics pauses while logistics routes assume the function of logistics spatial transference, logistics activities of transport and delivery

"Supported by Shandong Province, College of Humanities and Social Science Research Program (No. J13WG58) and Zhejiang Provincial Natural Science Foundation (No. 13YJC630221). carried out on the routing distribution, and transportation costs account for a majority of logistics costs, so the logistics routing optimization is the key to reduce logistics costs [1]. Based on the logic above, this article proposed ideas and methods of optimizing logistics routes by using the spatial interaction theory and demonstrated the practicality and feasibility of this method through analyzing the case of logistics routing optimization of blue and yellow zones.

\section{Theoretical Basis}

Regional logistics should be able to meet the needs of regional economic development at first based on the relationship between regional logistics and regional economy. Region involves a number of economies, the spatial interaction theory is a basic theory of explaining economic spatial linkage between economies, it mainly studies on locating potential energy, regional polarization and diffusion mechanism, spatial interaction model as well as the change and effect of factor flow. This theory can be used to explain whether the association exists, association strength and how to associate relevance between cities, between city and region, between regions, in addition the influence and influencing factors of the association strength and association way in the spatial system.

The gravity model is a mathematical expression of the 
spatial interaction theory. Gravitational interaction between cities is a key element of the gravity model. The urban flow is the economic activity generated by connection outside and the intensity of the urban flow is used to measure the connection of city from the outside world. The intensity of urban flow refers to the energy generated by urban extroverted function (agglomeration and radiation) and the number of mutual influence relations between cities. In this paper, we adopted the urban flow intensity to represent the force between single city and its adjacent city. Specific formula is:

$$
F=N \cdot E
$$

$F$ means the intensity of urban flow, $N$ means the city functional benefit, it is the actual impact generated by unit extroverted function among cities, $E$ means urban extroverted function, it is composed of economic activity generated by the city contacting with the outside world.

Considering the representation of indicators and data availability, this paper adopts the practitioners engage in export-oriented economic activity as indicators of the amount of urban functions. It is represented by the location quotient engaging in export-oriented economic activity. Specific formula is:

$$
L q_{i j}=\frac{G_{i j} / G_{i}}{G_{j} / G}(i=1,2, \cdots, n ; j=1,2, \cdots, m)
$$

If $L q_{i j}<1$, city $i$ department $j$ do not have external function, $E_{i j}=0$; If $L q_{i j}>1$ city $i$ department $j$ do have external function, because the allocation proportion of practitioners exceed the national allocation proportion, it can provide services outside the city area. Thus, the external function of city $i$ department $j$ can be expressed as:

$$
E_{i j}=G_{i j}-G_{i}\left(G_{j} / G\right)
$$

So the total amount of extroverted function of $m$ departments in city $i \quad E_{i}$ is:

$$
E_{i}=\sum_{j=1}^{m} E_{i j}
$$

The function efficiency of city $i$ can be expressed by GDP per capita:

$$
N_{i}=G D P / G_{i}
$$

So the intensity of urban flow of city $i$ is:

$$
F_{i}=N_{i} \cdot E_{i}=\left(G D P_{i} / G_{i}\right) \cdot E_{i}
$$

Defining the distance is another key factor of the gravity model, under the condition of market economy, the distance has alienated to the combination concept of monetary cost and time cost .Therefore, distance can be expressed as [2]:

$$
d_{i j}=\sqrt{\sum_{i=1}^{n} \lambda_{i j} c_{i j} T_{i j}}
$$

Including $i$ means the $i$ th way of transportation between $i$ and $j ; \lambda_{i j}$ means the weight of the $i$ th way of transportation between $i$ and $j ; c_{i j}$ means the monetary cost of the $i$ th way of transportation between $i$ and $j ; T_{i j}$ means the time cost the $i$ th way of transportation between $i$ and $j$.

\section{Study Design}

The general idea about routing optimization of regional logistics can be summarized as: The regional logistics routing optimization should be based on the logistics demand volume, according to the logistics demand volume, we can determine the regional logistics demand, then determine the supply ability of regional logistics route in light of the road traffic conditions. In the end, optimization recommendations can be put forward based on the matching of demand and supply situation of logistics route.

\subsection{Logistics Demand Analysis}

Regional logistics demand should include two parts, the first is to grasp the current logistics demand, and the second is the logistics demand forecast for the future. Considering the regional logistics demand is in order to meet the needs of the development of regional economy at first. When it comes to intra-region or inter-city, its logistics flow in a certain degree can represent the strength of the association between cities or within region, and the gravity model which belongs to the spatial interaction theory can reflect the strength of the association between cities or within region in order to measure the correlation between cities in the region. Then we can use the industrial structure analysis method (location quotient) to study the leading industry of the cities in the area, according to the leading industry to determine the main city logistics functional requirements, finally, analyzing the relation between the city industry cooperation to determine the city logistics demand at present, also in the future by setting high degree of correlation city as the object.

\subsection{Investigation of Logistics Supply}

To conduct a full investigation of the city logistics supply situation in the region, the investigation content includes the current logistics infrastructure supplies and the plans for the future supplies. Current supply situation is mainly to analyze the overview of the main logistics corridor in the region and to analyze main logistics nodes. Logistics activities of the logistics nodes are mainly concentrated in the logistics park, and the logistics node should be 
highlighted in the general situation of logistics park. The future supplies mainly based on the planning of regional and intra-regional city logistics.

\subsection{Optimizing Opinion}

Intra-regional correlation close ties to the city industry, the logistics route supply present situation and the future plan is the basis of the regional logistics routing optimization. Experience measures suitable for this region can be refined to put forward the regional logistics routing optimization and improvement opinions through analyzing and summarizing the successful cases of international and domestic regional logistics.

\section{Application Example}

In 2009 the state council approved the Yellow River delta efficient ecological economic zone development planning, and in 2011 approved the Shandong peninsula blue economic zone planning. So far the integrative development of the blue and yellow economic zone has become the focus of attention from all walks of life and it is also inseparable from the support of modern logistics. So this article took the optimization of the blue and yellow zone logistics route to illustrate the applicability and feasibility of the gravity model.

\subsection{Urban Gravity of the Blue and Yellow Economic Zone}

Using export-oriented department practitioner index to measure the intensity of urban flow, urban flow intensity of Dongying, Weifang, Dezhou is higher, it shows that the export-oriented economy of the city, in addition to meeting the local needs and more surplus capacity to undertake external demand.

There are four main modes of transportation between cities, highway transportation, railway transportation, water transport and air transport, and yellow blue economic zone is in the range of road transportation economic mileage, a large number of transportation is assumed by road transportation in the blue yellow economic zone, so this article selected the inter-city highway as basis of the main distance. Distance formula can be expressed as:

$$
d_{i j}=\sqrt{c_{i j} T_{i j}}
$$

Including $c_{i j}$ means the monetary cost of the road transportation between $i$ and $j ; T_{i j}$ means the time cost of the highway transportation between $i$ and $j$.

Monetary cost of highway transportation was expressed by road freight rate, nearly three months of 218 times transport data was collected through the transportation enterprise investigation. Statistics showed that the road freight rate floating 0.20 yuan/ton.Km nearby, of which $71 \%$ of freight rate fluctuating in the range of 0.20 +0.02 , the concentration degree of the freight rate was higher. The remaining $29 \%$ of the data was divided into two groups, higher than the average and below average. It was found that the higher freight rate in respects of transportation distance had significant difference with the rest of the sample. Then, regression analysis was carried out on the transportation by using the transportation distance and vehicle type, etc. It was found that the coefficient of determination was as high as 95\%, after the variable vehicle type added, the coefficient of determination increased less than $1 \%$. So it can be seen that transportation cost mainly related to the transportation distance. According to the results of regression, the monetary cost of transportation is a function of the transport distance and it can be concretely expressed as:

$$
c_{i j}=0.98 * D_{i j}
$$

Including $D_{i j}$ means the actual physical distance between $i$ and $j$.

This article used baidu map (http://map.baidu.com) to query the distance between $i$ and $j$. As the distance was the main factors influencing the transport monetary cost, this article chose the shortest distance between $i$ and $j$ as query conditions when querying on the baidu map, in this way, the distance between city and city in the blue yellow economic zone can be obtained. At the same time, Shandong province traffic tourist map published by map publishing house of Shandong province in 2012 was also collected to verify the accuracy.

Vehicle running speed is important influence factor in the vehicle operating costs, and the main factor influencing the vehicle running speed is road technology level. As the roads with different technology levels have different requirements in the design of surface evenness, Slope, turning radius, the higher the road technical level is, the faster the speed is, and the greater the impact made on operating costs [3]. According to the road technology standard of the People's Republic of China (JTGB01 2003) which regulated different types of road driving speed, and combined with the blue economic zone road actual situation, set the highway $120 \mathrm{~km} / \mathrm{h}$, state road 80 $\mathrm{km} / \mathrm{h}$, provincial highway and the following road 60 $\mathrm{km} / \mathrm{h}$. The freight time (unit: h) between cities can be calculated by Using the various road mileage between each city.

According to the gravitational model of cities, setting urban flow intensity as the interaction force of each city, using the distance between the cities, computing the mutual attraction between cities, Table 1 can be obtained.

From Table 1, the gravity of cities in the blue and yellow economic zone in total to Weifang, Dongying, Dezhou, Qingdao, Rizhao, Yantai, Zibo, Weihai in a de- 
Table 1. Attraction between cities in blue and yellow economic zone.

\begin{tabular}{cccccccccc}
\hline City & Qingdao & Yantai & Weifang & Rizhao & Weihai & Dongying & Zibo & Dezhou \\
\hline Qingdao & - & 17.41 & 67.64 & 71.25 & 4.50 & 33.45 & 2.06 & 25.54 \\
Yantai & 17.41 & - & 19.00 & 8.73 & 30.06 & 12.82 & 0.86 & 8.77 \\
Weifang & $\mathbf{6 7 . 6 4}$ & 19.00 & - & 34.16 & 4.55 & 181.07 & 11.03 & 167.96 \\
Rizhao & $\mathbf{7 1 . 2 5}$ & 8.73 & 34.16 & - & 2.23 & 23.88 & 1.98 & 16.08 \\
Weihai & 4.50 & 30.06 & 4.55 & 2.23 & - & 3.53 & 0.26 & 2.47 \\
Dongying & 33.45 & 12.82 & $\mathbf{1 8 1 . 0 7}$ & 23.88 & 3.53 & - & 32.63 & 167.97 \\
Zibo & 2.06 & 0.86 & 11.03 & 1.98 & 0.26 & 32.63 & - & 32.65 \\
Dezhou & 25.54 & 8.77 & $\mathbf{1 6 7 . 9 6}$ & 16.08 & 2.47 & $\mathbf{1 6 7 . 9 7}$ & 32.65 & - \\
\hline
\end{tabular}

scending order, after taking the city distance into account, certain differences existed in the evaluation of the sorting result with urban flow intensity. In addition, from the point of gravity between cities (such as the bold cells in Table 1), two big gravity group formed, one is centered in Qingdao, and the gravity linear group was composed of the gravity between Qingdao and Weifang, also the gravity between Qingdao and Rizhao. Another one made the gravity between Weifang and Dezhou, and the gravity between Weifang and motivation coherent, formed a closed gravity group through the relationships between Dongying and Dezhou. As shown in the Figure 1.

\subsection{Urban Industries and Logistics Demand Research on Blue and Yellow Economic Zone}

\subsubsection{Blue and Yellow Economic Zone Primary Industry Characteristics and the Logistics Requirements}

1) The primary industry characteristic industry analysis

From the perspective of industry specialization and scale, Dongying and Binzhou's cotton industry, Weihai's fisheries, Rizhao's oil industry, Yantai's fruit nut beverage industry and Dezhou's livestock industry have advantage in industry specialization and scale. Although the specialization of Qingdao's fisheries and Weifang's vegetables is not very prominent, ratio exceeded $20 \%$ in the primary industry of Qingdao and Weifang. Flowers and other horticultural compared with other agricultural industry in Zibo, the scale degree is not high, but compared with other cities, professional advantages are very obvious. From this view, the leading industries of blue and yellow zone cities primary industry are respectively shown in Table 2.

2) Agricultural Cooperation Analysis

The first group (Weifang-Dongying-Dezhou) analysis of the agricultural cooperation: The first group composed
Table 2. City characteristic industry in the primary industry.

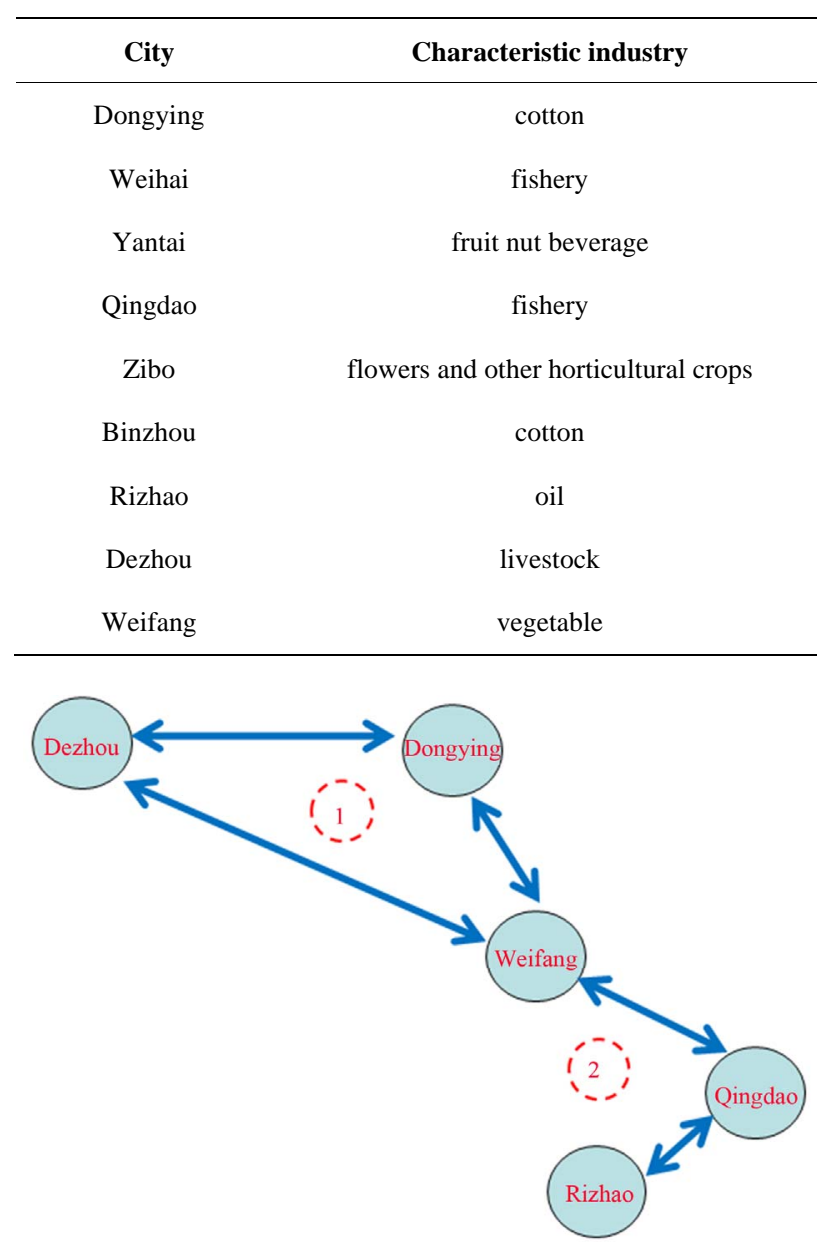

Figure 1. Gravity group of blue and yellow economic zone.

of Weifang, Dongying and Dezhou covers four cities (Weifang, Dongying, Binzhou and Dezhou), and Weifang, Dongying, Binzhou and the county Laoling and Qingyun belong to the category of yellow economic zone. In view of the situation of urban agriculture industry lo- 
cation quotient in the blue and yellow economic zone, the agricultural characteristic industries of Weifang, Dongying, Dezhou respectively are vegetables, cotton and livestock. Vegetables and livestock sales link needs the support of cold chain logistics, so it is suggested that the cold chain logistics system should be established and developed in the first group (It was consistent with the cold storage needs of ecological animal husbandry industry chain which was in mentioned the Dongying 12th five-year plan). Dongying and Binzhou's cotton advantage is obvious, and the Binzhou's textile industry location quotient is higher in its secondary industry, so the integrative development of the primary industry and the secondary industry can be formed in the first group. Binzhou's textile industry should be set as the core to established industrial chain (cotton production-cotton processing - sale). The additional value of cotton can be improved through the textile and the industry chain can extend forwards and backwards. Backward can develop bamboo forest planting (Binzhou Haosheng Group which has industrial base), forward can develop clothing industry.

The second group (Weifang-Qingdao-Rizhao) analysis of the agricultural cooperation: Qingdao characteristic agriculture is fishery, it also needs the support of cold chain logistics to achieve high additional value. So the cold-chain logistics network of the first group is supposed to extend to Qingdao, Form cold chain logistics network system that its core logistics node is Weifang, main logistics nodes are Qingdao, Weifang and Dezhou.

\subsubsection{Blue and Yellow Economic Zone Secondary Industry Characteristics and the Logistics Requirements}

1) The secondary industry characteristic industry analysis

The proportion of each city industry in its secondary industry shows the scale of the industry in this city, and the location quotient of the blue and yellow zone shows the degree of specialization of the industry in the region. Considering the double perspective (Specialization and scale), the main industries of cities are shown in Table 3.

2) The secondary industry group cooperation analysis

The first group (Weifang-Dongying-Dezhou) analysis of the industry cooperation: As the degree of specialization of agricultural products and byproducts process is only 0.8 , it is necessary to continue improving its industry specialization, but the specialization of industry needs a process. Therefore, in the short term, the agricultural products and byproducts processing of Binzhou need to rely on the processing capacity of Weifang.

The second group (Weifang-Qingdao-Rizhao) analysis of the industry cooperation: The black metal smelting and rolling processing industry of Rizhao have not yet been forming, the location quotient is only 0.1 which cannot be self-sufficient. And the location quotient of ferrous metals mining and dressing is 11.91 . When it comes to Zibo, the location quotient is 6.02 , but the location quotient of the Black metal smelting and rolling processing is 2.61. Compared with Zibo, the scale of

Table 3. Main industries of cities in secondary industry.

\begin{tabular}{|c|c|}
\hline City & Both specialty and strength \\
\hline Qingdao & $\begin{array}{l}\text { Developmental Emphases: transportation equipment manufacturing industry; } \\
\text { Electrical machinery and equipment manufacturing industrialization }\end{array}$ \\
\hline Yantai & $\begin{array}{l}\text { Communication equipment, computers and other electronic devices; Non-ferrous metal smelting and rolling } \\
\text { processing industry; Developing the nonferrous metal industry acquisition and processing of industrialization }\end{array}$ \\
\hline Weihai & $\begin{array}{l}\text { Manufacture of Rubber, artware and other Manufacturing, Agricultural Products and Byproducts Processing; Promoting } \\
\text { instrumentation of cultural and educational sporting goods manufacturing and cultural office machinery manufacturing scale }\end{array}$ \\
\hline Rizhao & $\begin{array}{l}\text { Ferrous Metals Mining and Dressing, Wood processing and products, Metal Products, Electric heat production and } \\
\text { supply industry, agricultural Products and Byproducts Processing; Improving the degree of specialization food processing }\end{array}$ \\
\hline Dongying & $\begin{array}{l}\text { Petroleum and Natural Gas Extraction, Oil processing and coking and nuclear fuel processing industry, } \\
\text { Chemical raw materials and chemical manufacturing, Rubber products Developmental Emphases: } \\
\text { Oil production, processing and deep processing industry industrialization }\end{array}$ \\
\hline Weifang & Developmental Emphases: Industrialization of agricultural food processing \\
\hline Binzhou & Textiles, leather and fur feathers (fine hair) and manufacturing Developmental Emphases: Textile industry industrialization \\
\hline Zibo & $\begin{array}{l}\text { Chemical raw materials and chemical manufacturing; Nonmetal Mineral Products; } \\
\text { Oil processing and coking and nuclear fuel processing industry }\end{array}$ \\
\hline Dezhou & Extractive industry \\
\hline
\end{tabular}


Rizhao black metal smelting and rolling processing industry is too small and metal logistics cost is higher, so it is the best way to process nearby. As Rizhao is close to Qingdao, it is the lowest logistics cost strategy to choose Qingdao as downstream processing site of the black metal smelting and rolling processing.

From the perspective of the cooperation of the first group and second group, it is prominent in the first group that Binzhou cooperates with Weifang and it is the same with the cooperation of Qingdao and Rizhao in the second group. Because the distance between Binzhou and Weifang is close as well as Qingdao and Rizhao, which is in the range of road transportation economic mileage, it is necessary to strengthen the road transport capacity between Binzhou and Weifang, Rizhao and Qingdao.

\subsection{The Present Situation of Logistics Supply of Blue and Yellow Economic Zone}

The distance between cities in the main group which belong to the blue yellow economic zone can be obtained, as shown in Table 4.

\subsection{Blue and Yellow Zone Logistics Route Optimization Suggestions}

From the distance between main group cities of blue and yellow economic zone, the highway distance between two cities is shorter than the national road distance, except Weifang-Binzhou and Weifang-Dezhou. The conditions and the highest speed limit of highway are superior to the national road, so it can largely save transportation time when choosing highway. The highway between Weifang and Dezhou is equivalent to going around the two edges of the rectangle of which diagonal is Weifang to Dezhou, so the distance is longer than the national road. Therefore, we suggest establishing transverse connection between G3 Jingtai highway and G25 Changshen highway. So it can not only shorten the distance from Dezhou to Weifang, but also benefit the three cities (Binzhou, Jinan and Dezhou).

Table 4. The distance contrast between mainly contrast group cities of blue yellow zone.

\begin{tabular}{ccc}
\hline City-City & $\begin{array}{c}\text { Highway } \\
\text { distance }\end{array}$ & $\begin{array}{c}\text { National road } \\
\text { distance }\end{array}$ \\
\hline Weifang-Dongying & $106 \mathrm{~km}$ & $127 \mathrm{~km}$ \\
Dongying-Dezhou & $219 \mathrm{~km}$ & $254 \mathrm{~km}$ \\
Dezhou-Weifang & $233 \mathrm{~km}$ & $179 \mathrm{~km}$ \\
Binzhou-Weifang & $180 \mathrm{~km}$ & $134 \mathrm{~km}$ \\
Rizhao-Qingdao & $134 \mathrm{~km}$ & $188 \mathrm{~km}$ \\
Qingdao-Weifang & $135 \mathrm{~km}$ & $179 \mathrm{~km}$ \\
\hline
\end{tabular}

In addition, except the logistics routes, the logistics node construction should be given full consideration to the group cooperation between two cities, Such as the demand for cold chain logistics network in the group cooperation of primary industry, and the demand for railway logistics network in the group cooperation of secondary industry.

\section{The Conclusion and Prospect}

This article studies on logistics routing optimization by applying the demand of the regional economic development as the starting point, using spatial interaction theory, building a method of a regional logistics link optimization based on the gravity model, and taking blue and yellow zones as the background to illustrate the rationality and feasibility of this method. Supporting the economic development is only one of the goals of the regional logistics development. As an independent economic activity, logistics is also one component of regional economies. Therefore the research on logistics route optimization whose goal is the future logistics industry development has certain theoretical value and practical significance.

\section{REFERENCES}

[1] H.-Q. Hu, J. Zhou and Z.-Z. Zheng, "Blue and Yellow Zone Logistics Network Nodes Optimization Research,” Shandong Social Science, Vol. 2, 2013, pp. 116-119.

[2] W. Zhou, B. Zhang, B. Zhang, et al., "Spatial Relationship between Dual-core Cities Based on Gravity ModelA Case of Chengdu and Chongqing City," Resource Development \& Market, Vol. 26, No. 11, 2010, pp. 82-85.

[3] W.-L. Lan, S.-P. Tan and Y.-Q. Ma, “An Analysis of Costs of Roads in different Grades," Journal of Wuhan Institute of Shipbuilding Technology, Vol. 6, 2009, pp. 74-78. 